\title{
Undergraduate Research Projects Supervision at the University of Namibia's Rundu Campus: Supervisors' Stances
}

\author{
Natalia S. Intja ${ }^{\text {a }}$, Oiva S. Nauyoma ${ }^{\mathrm{b}}$ \\ aEmail: nreino@unam.na \\ ${ }^{a}$ Lecturer in the Faculty of Education and Human Sciences, Department of Intermediate and Vocational \\ Education, University of Namibia's Rundu Campus \\ ${ }^{b}$ Lecturer in the Faculty of Education and Human Sciences, Department of Early Childhood Education and \\ Care, University of Namibia's Rundu Campus
}

\begin{abstract}
This study aims to establish the perceptions of Bachelor's degree Honours lecturers regarding research project supervision; capture challenging areas in research project supervision with a view of improving research project supervision and expand a repertoire of actions and responses. The research presented in this paper explores supervision of students' research projects from Vygotsky's Zone of Proximal Development (ZDP) theory and Kolb's experiential learning theory thrusts. This is a qualitative approach embedded within a phenomenological interpretive where twenty research supervisors and twenty final year students on full-time and part-time mode were interviewed using the semi-structured interview guides. The paper drew on both document analysis and content analysis. The data were interpreted using the theoretical lenses of the study's primary objectives, and conclusions and recommendations were derived from the interpretation. The findings of the study reveal that the key challenges of research supervision for the supervisors lie between the administration part of the research and the expertise. The study recommends that the University of Namibia should start with research modules from year one to year four, this is because one year of doing research is not enough as students learn differently. Moreover, research proposals should form as students' prerequisites before they progress to the fourth year.
\end{abstract}

Keywords: Undergraduate; supervisor; supervisees; Research Projects; Zone of Proximal Development; University of Namibia 


\section{Introduction}

Research supervision of students' research projects in the final year has been a responsibility of every lecturer at the University of Namibia. For this to work, students are assigned to supervisors who are entrusted with the responsibilities of supervising students throughout the process of the project, and undergraduate students are obliged to undertake a research project to demonstrate writing skills and independence as researchers (Elmabruk \& Bishti, 2020). Despite all these, it appears to be a rapid increase in the number of undergraduate students researching at the University of Namibia (UNAM). Students in their final year of the four-year Bachelor's degree program at UNAM are required to complete a substantial piece of individual research that is ten pages in length. The research is frequently referred to as the degree program's culmination, as it consolidates the student's understanding of the more in-depth approach to learning through a review of existing knowledge, identification of areas for additional research, data collection and analysis, and writing up their findings. As such, students are required to conduct independent research at this level while being supervised by an academic staff member.

Furthermore, academic supervisors are expected to assume a variety of roles and responsibilities throughout the supervision process. Brewer et.al. (2012) explain that undergraduate research forms an integral part of students' academic progress as it represents an important component of obtaining the degree. Ndlangamandla (2017) asserts that the majority of universities face a staffing shortage of academics capable of supervising research projects, the majority of which are at the bachelor's degree level. As a result, supervisors face numerous challenges throughout the undergraduate supervision process and in providing accurate feedback to supervisees. It seems as though the supervisor's level of qualification and supervisory experience are critical components of the supervision process. As such, many supervisors draw on their own supervisory experiences, which serve as a guide throughout the supervision process. Supervisors explained their perceptions of effective supervision as to balance multiple supervisory roles, such as teaching, mentoring, supporting, and evaluating, in terms of facilitating learning for students in a variety of contexts (Brewer. et al. 2012). To accomplish this, supervisors must be committed to assisting students by providing effective feedback and taking decisive action against plagiarism. Roberts and Seaman (2018) suggest that certain difficulties may steer the supervision process in undesirable directions, such as concern about the supervisor's responsibilities and a shift partnership in student relationships.

Winchester-See, Rowe, and Mackaway (2016) allude that student supervision is a key factor underpinning the success of research projects at institutions of higher learning. In a Malaysian study conducted by Razali, 
Hawe, and Dixon (2020) about how undergraduate students can be supervised posits that supervision is intrinsic to institutional-based research projects as it acts as a catalyst for the successful execution and completion of said projects. If students are to be independent in research and learning, they have to experience a supervision approach that supports their engagement in learning dialogues alongside their supervisors. Razali, et al. (2020) define research supervisor as an academic expert who supports students in their academic journey as the more knowledgeable other.

Olsson and Hallberg (2018) argue that institutions should support lecturers to develop their own academic writing identities in education, also as supporting them to figure more effectively as writing developers within their subject specialisms, or collaboratively with specialist writing development staff. They further maintain that the possibility of adapting to students' needs and developing students' writing increases if the supervisor is skilled as an academic writing developer. Academic writing should be an important and supported activity for the student during their time at the university. Students do benefit from a holistic and embedded approach to writing development.

Whilst there is a plethora of literature about undergraduate research supervision internationally (Olsson \& Hallberg, 2018; Winchester-See, Rowe \& Mackaway, 2016; Reguant, Martínez-Olmo, \& Contreras-Higuera, 2018); Lee, 2007; Roberts \& Seaman, 2018; Muthanna \& Alduais, 2021; Vereijken, van der Rijst, van Driel \& Dekker, 2018) and nationally (Elmabruk \& Bishti, 2020; Makoni, 2021; Mushoriwa \& Nyakutse, 2014;) there seems to be a dearth of literature in the local context which is Namibia, specifically at the University of Namibia's Rundu Campus. Little is known about what may seem to be an ambivalence among lecturers about how to support the writing aspects during a program of a research project in their role as supervisor. It is against this background that this study explores how supervisors perceive their roles and responsibilities in their supervisory activity in the Bachelor level of research project's writing process, the challenges they encounter as they supervise their students, and suggest mechanisms that may be put in place to help smoothen the undergraduate research supervision process. This kind of analysis may lead to better collaboration between the supervisor, and the student and in turn to a higher quality of written final research projects and to grasp the knowledge of writing research papers independently by students. 


\section{Theoretical Framework}

The research presented in this paper explores supervision of students' research projects from Vygotsky's Zone of Proximal Development (ZDP) theory and Kolb's experiential learning theory thrusts. The Zone of Proximal Development describes and analyses supervision in terms of a More Knowledgeable Other (supervisor) scaffolding the novice (students). Whereas Kolb's experiential learning theory presents a way of constructing and alternation in the course of study and provide a concrete understanding of how a class or a whole course of study can be taught to have better learning by the students (Sharlanova, 2004).

\subsection{Vygotsky's Zone of Proximal Development (ZPD) and Research Supervision}

The ZPD is that the gap between what a student has already mastered, his actual level of development, and what he is able to do when given educational support, called potential development. The ZPD is believed to means the difference between the student's capacity to unravel problems on his own, and his capacity to unravel them alongside receiving assistance (Schutz, 2004). All the tasks that a student can do alone can be referred to as developmental level. On the other hand, ZPD comprises a scaffolding process which is performing the activities with the help of a supervisor, a parent, caretaker, language instructor, or another peer who has already mastered that particular function. The notion of the ZPD reflects Vygotsky's view on the nature of human development and the interrelation between learning and development. Learning, which is distinct from development, may lead to development and ZPD is the abstraction that describes the mechanism and potential effect of learning on development (Tello, 2012). Bazrafkan, Yousefy, Amini, and Yamani (2019) affirm that supervision may be a well-defined interpersonal relationship between the thesis supervisors and their students. Substantively, Agricola, Prins, van der Schaaf and, van Tartwijk, (2021) research supervision is a complex and subtle form of teaching. In this study, research supervision is regarded to be a teaching process for the supervisor and a learning process for the scholar. Contextualizing research supervision to ZPD entails that students are supported into conducting a research project by a more knowledgeable other who is the supervisor. To add, quality supervision is closely rendered to the students until such a time that they can be left alone to write the research project on their own, while the supervisor only plays the role of a facilitator. 


\subsection{Kolb's Experiential Learning and Research Supervision}

Kolb's theory is affirmed as a learning theory that confirms all main aspects of active learning. It provides a theoretical argument of independent learning, learning by doing, work-based learning, and problem-based learning. The theory has a vast range of applications, including helping students realize themselves, helping teachers become reflexive teachers, identifying the learning styles of students, and developing of key teacher skills. It also helps within the development of group project work (Sharlanova, 2004). Using this theory, students are given a fair chance to learn by doing in terms of how to research with the help of their assigned experienced supervisor. The advantages of Kolb's theory are often summarized within the following way:

- Provides ready directions for application.

- Gives directions for the required range of education methods.

- Provides an effective connection between theory and practice. Offers a theoretical argument of things that a lot of teachers apply and wish advice on the way to improve their practice.

- Formulates the importance of students to reflect and the importance of providing feedback to stimulate their studying.

- Helps to rationalize the way of mixing learning styles in order that learning can become simpler.

- with none effort are often utilized in all subject areas.

- Can be used by an individual, by teams, or by whole organizations.

- are often utilized in a specific lesson, session, or long course of study.

Richardson, Eysenck, and Warren Piper (1987) say that "the concept of experiential learning means learning by reflection on the experience". Without reflection on experience, students are in peril to still make an equivalent mistake over and once again. But when the students get quality and adequate support from their supervisors they tend to work on the comments given within their research project drafts and write a quality paper. Henceforth, the essence of Kolb's model is just a description of the learning process, which is pictured as a cycle made of four phases. In the model, it's shown how experience is transformed through reflection in ideas and ideas, which successively are used for active experimenting and selection for a replacement experience. Kolb connects with those four phases the Concrete Experience (CE) -doing, Reflexive Observation (RO) - observing, Abstract Conceptualizing (AC) - thinking, and Active Experimenting (AE) planning. They follow one after another during a cycle (Fig. 1). 


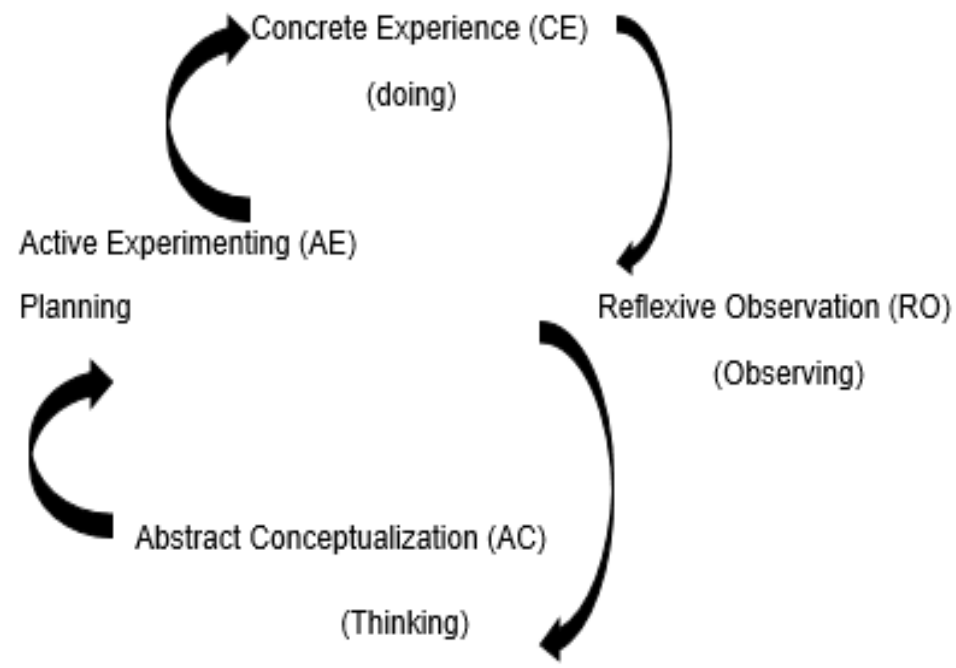

Figure 1. Kolb's model espoused from Sharlanova (2004).

2.2.1 Contextualizing the Kolb's Model of Experiential Learning in research supervision

Concrete Experience - the student is seen as an active participant. This means that the student is the one who is being supervised to write a final research project and with such, they are termed active participants because they are fully engaged in the research writing process of their projects. They do the activity without reflecting.

Reflexive Observation - the scholar consciously reflexes on experience. After the students are told in the educational Research module in the third year coupling it with the help they get from their assigned supervisors they are in a good position to learn how to research and implement it in their research projects.

Abstract Conceptualizing - the student tries to conceptualize theory or model of what he has observed. In this case, students observe, for instance how to cite and reference sources and they tried it on their own.

Active Experimenting - the scholar tries to plan the way to test the model, or the idea, or the plan for the forthcoming experience. In this case, the students are given comments in form of track-change or any other feedback mode and they work independently to write their research projects. 


\section{Research Objectives}

The objectives of the study were to:

3.1. establish the perceptions of Bachelor degree Honours lecturers regarding research project supervision;

3.2. capture challenging areas in research project supervision with a view of improving research project supervision;

3.3. expand a repertoire of actions and responses.

\section{Literature Review}

Establishing from the research objectives of this paper, the following themes were reviewed using the existing scholarly literature; a synopsis of the roles and responsibilities of undergraduate research supervisors, roles and responsibilities of undergraduate supervisees (students), dilemmatic space of research supervisors, and research supervision styles.

\subsection{A synopsis of the roles and responsibilities of Undergraduate Research supervisors}

Undergraduate research supervision at UNAM campuses appears to be a critical practice valued by some lecturers as a sign of a student acquiring a variety of skills. On the other hand, some believe that lecturers should be compulsory to supervise students at the university level (Bak, 2011). However, Bastalich (2017) argues that making undergraduate research mandatory will disadvantage students who lack the aptitude to pursue this course of study. One caveat to bear in mind is that no undergraduate research is ever published, therefore the undergraduate research should be optional, allowing the less intellectually learning students a choice (Bastalich, 2017). Moreover, undergraduate research appears to be more practical than theoretical, allowing students to select their topic of study and develop their own unique individual work. The supervisor's role and responsibilities are to comprehend how the research makes sense of the academic world, particularly their experience and its value (Roberts et al., 2018). With this in mind, it is critical for the undergraduate supervisor to consult with experienced professionals in the field of research before taking on the role of supervisor. Alternatively, the undergraduate supervisors may wish to consult the substantial body of literature devoted to educating professionals about the benefits of an undergraduate research assistantship (Grover, 2006). 
Furthermore, to be a successful research supervisor, the supervisee should be capable of completing a research project with a pertinent research topic, mastering the techniques necessary to investigate the topic, correctly applying these techniques, and presenting the findings in an appropriate manner (Grover, 2006). As such, the supervisor must instill in the supervisee the ability to evaluate and re-evaluate their work in light of current events. It is noticeable that the successful completion of a research project is as much a function of the student's intelligence and training as it is of the supervisor's ability. Mouton (2001) asserts that the supervisor's responsibility is to guide and provide the supervisee with the necessary psychological support amongst the others. Additionally, Bartlett and Mercer (2001) describe a research supervisor's role as a confidant with the source of intellectual inspiration, grant application writer, navigator of institutional tangles, change manager, personal motivator, and editor of the research report.

Interaction between the supervisor and students is crucial in any working environment, and it helps students build their ability to be open to the scholarly argument while also developing critical thinking skills. Following Ndlangamandla's (2017) views that the supervisor is involved in the research project to develop techniques to help students cope better with their research projects. This means that students should be able to read, assess, and apply the literature to their research project. At the most fundamental level, one of the supervisor's primary objectives is to examine a variety of research resources that may be referenced and that will aid the supervisee in completing the project.

Moreover, Razali, et al. (2020) maintain that supervisors should possess knowledge in students' areas of research and research methods as well as to guide students in structuring and accomplishing a feasible research project. Whether or not supervisors should possess knowledge in students' areas of research, research methods and the need to guide students in structuring and accomplishing a feasible research project is what this study sought to establish. They further supplement that the role of a supervisor also includes being the source of knowledge and/or information providing assistance to students with administrative aspects of their research such as structuring a research timeline.

In addition, supervisors are considered to be important figures in developing students' independence (Reguant et al., 2018). Todd, Bannister, and Clegg (2004) have argued that students' independence in research doesn't come naturally - it must be developed and supported by supervisors. Supervision also requires supervisors to support the emotional and motivational needs of students in the research journey (Lopatto, 2003). A supervisory relationship that's built on trust has been perceived as important to supervisors. 
Supervisors believe that when students have trust in them, students will be more open to sharing issues they are facing, be it academic-related issues or personal ones (Roberts \& Seaman, 2018a). Likewise, students believe that supervisors need to be approachable, available, and be supportive of their emotional needs (Roberts \& Seaman, 2018b). Interestingly, studies have also revealed that students perceive supervisors' concerns about their progress as an indication of support and as a source of motivation.

Furthermore, the supervisor is thus expected to wear several hats and juggle several roles. Makoni (2021) identified ten key roles of research supervisors. These include:

- A director that assists with the identification and fine-tuning of a researchable topic, and appropriate methodology;

- A facilitator who will provide opportunities to tap into resources, networks, also as subject expertise;

- An adviser to supply guidance and assistance with technical problems;

- A teacher to expose the student to various research methodologies and techniques, academic writing, use of research databases, and related activities;

- A guide to hold the student's hand through the process of writing the proposal and respective chapters, coming up with a reasonable timeline concerning expected milestones and time to completion, as well as advise on data collection and analysis;

- A critic who will give honest, timeous, constructive feedback on submitted work or ideas exchanged;

- A freedom giver which will be flexible enough to permit the scholar to explore the doctoral journey independently;

- A supporter who will remain committed to the project ahead, and constantly encourage the student;

- A friend that will extend an ear to listen and shoulder to cry on for matters that affect the student's wellbeing, particularly those of a non-academic nature;

- A manager that will oversee the project from inception to completion, periodically checking and monitoring progress.

\subsection{Roles and responsibilities of undergraduate supervisees (students)}

Razali, et al. (2020) postulate that students are expected to be committed and be independent in doing their work. More so, students have a ground role of suggesting a research topic to the supervisor and research about the literature underpinning the research interest before they meet with their supervisors. Furthermore, students still have the role to execute the duty of writing the whole research project whereby their supervisor will just be the facilitator of the whole process. Students got to prepare tangible materials to be discussed in 
supervision meetings like ideas or drafts of works-in-progress (Todd et al., 2006). Correspondingly, students consider that if they're to finish the scientific research on time, they have to hold out the research work responsibly and work consistently. Again, students should carry out project-related tasks on their own without being overly dependent on supervisors to direct them or do the work for them (Todd et al., 2006).

\subsection{Dilemmatic Space of Research Supervisors}

Using the background of supervisors' goals in research supervision and their perceptions of what constitutes undergraduate supervision, Vereijken, et al. (2018) contend that supervisors might experience a dilemma between providing students with research guidance and providing answers to students. Substantively, some supervisees might study the way their supervisor reason and handle questions and play a mind game by asking the supervisor questions that might make him disclose answers to students and by so doing, the students are denied the platform to learn independently and be reflective thinkers.

\subsection{Discourses of Research Supervision}

The way supervisors perceive their role and responsibilities of supervision enables them to choose how they supervise their students. Some supervisors assume a more directive role, whereas others prefer to empower their supervisees to decide the course of their work and progress. Grant (2005) proposed three styles of supervision as cited in Razali, et al. (2020) The trad-supervision, techno-supervision and psy-supervision.

\subsubsection{The Trad-Supervision}

Trad supervision revolves around academic achievement and competencies. The trad-supervisor is seen as the More Knowledgeable Other (MOK), whereas the trad-students are perceived to be the absorbers of knowledge from the trad-supervisor. As such they are deemed passive participants and recipients in the research process. The trad-students are always seen as loyal and submissive subjects to their supervisors aiming to timely completion of the project.

\subsubsection{The Techno-Supervision}

The academic parts of research are the focus of techno-supervision. However, with techno-supervision, the focus is on improving students' research skills and competencies. This type of supervision is common in 
disciplines or fields of study that follow the scientific method and the positivist research paradigm. In technosupervision, the power relationship is asymmetrical, with techno-supervisors acting as expert scientists who utilize supervision as a platform to pass on their technical knowledge and research skills (Holmberg, 2006). Techno-students are viewed as inexperienced individuals who require detailed guidance and training from techno-supervisors. Supervisor-centric supervision is used, with techno-supervisors guiding techno-students through the research process. This supervisor-centric strategy frequently leads to the development of students' reliance on their supervisors, which works against the promotion of students' research and learning independence. The academic parts of research are the focus of techno-supervision.

\subsubsection{The Psy-Supervision}

The academic parts of research are the focus of techno-supervision. The ePsy-supervision, on the other hand, recognizes the academic and pastoral components of learning in techno-supervision. The power differential between psy-students and psy-supervisors is nearly equal. Psy-supervisors serve as "resource[s], not oracle[s]" (Mackinnon, 2004, p. 398) who guide students through their research process. Meanwhile, psystudents are seen as novice researchers with the ability to evolve into independent researchers over time (Grant, 2005). The dialogical engagement and communication between the two parties is at the heart of psysupervision. This type of engagement aids in the development of rapport and trust. As a result, both parties can talk about their aspirations and challenges, which might range from academic to socio-emotional issues.

\section{Methodology}

A study is a qualitative approach embedded within a phenomenological interpretive. Semi-structured interviews with the research supervisors were conducted at the UNAM Rundu campus. Face-to-face interviews were conducted with a purposively selected sample of twenty full-time academic staff members at the School of Education. Additionally, twenty final year students were interviewed telephonically both fulltime and part-time students. Similarly, the paper drew on both document analysis and content analysis. The data were interpreted using the theoretical lenses of the study's primary objectives, and conclusions and recommendations were derived from the interpretation. 


\section{Findings}

This section discusses the results that were generated from the qualitative part of this study, in which the following specific research objectives were explored:

- To establish the perceptions of Bachelor degree Honours lecturers regarding research project supervision;

- To capture challenging areas in research project supervision with a view of improving research project supervision;

- To expand a repertoire of actions and responses.

\subsection{A summary of collective interview responses and discussion from the lecturers}

The interview questions were turned into themes and they are as follow;

\section{Theme 1: The Definition of Research Supervision}

When asked to define the term research project supervision, most of them explained that research project supervision is the type of supervision were a supervisor Is assigned to a tutee or tutees with the aim of guiding them on how to conduct their research projects from choosing a research topic, writing a research proposal and the final project.

\section{Theme 2: Expectations of supervisors in supervising undergraduate students}

The supervisors were of the opinion that as supervisors they should possess the expertise to support students in their research journey. They further underscored that they should possess knowledge in students' areas of research and research methods. Supervisors need to guide students in structuring and accomplishing a feasible research project. This task entails guiding students in deciding on the focus of the research, advising students on the feasibility of their research methodology and introducing students to related literature. Some supervisors have also mentioned that they should provide assistance to students with administrative aspects of their research such as structuring a research timeline. From supervisors' points of view, students especially those who are undertaking independent research for the first time might not have an adequate understanding of the nature of a research project. Thus, supervisors consider it crucial to develop students' understanding of the technical aspects of research especially through one-to-one meetings at the early stage of supervision. Students and supervisors, therefore, expect the latter to play a more directive role at the beginning of supervision. 
Interestingly, some supervisors regard themselves as a "dictator" when describing their role at this early stage of a research project.

\section{Theme 3: Challenges experienced by research project supervisors}

When asked to state the challenges which they encounter as they supervise the research students, most of them said that they are not confident enough to supervise the research projects of students this is because they were never trained on how research supervision is done and they only see a list of students provided to them which they need to supervise without knowing where to start. And they also said that some students assigned to them do not fall under their research areas of interests and as such they have little knowledge to advise their students regarding the content of the paper but they are left with no option but to rely on what their tutees provide. Another challenge is that since the supervision is mostly done online, some students do not attend the meetings that they call and decide to write everything on their own and present the final paper to the supervisors. Henceforth, the research project coordinator does not communicate to tutors about what is expected of them verbally but he only sends communiques via e mails which is not enough to assume that everybody has understood of what should be done and how it should be done.

6.2. A summary of collective interview responses and discussion from final year full time and part time students

The final year students were also interviewed and the following is what they had to say regarding their expected roles as researchers and that of their supervisors.

Supervisors impart and explain research concepts, assist students in applying knowledge and skills in research and provide feedback on the content and technical aspects of the work. Students expect supervisors to provide constructive feedback about their work and progress, in particular with reference to drafts of their research proposals and projects. They further said that they expect their supervisors to be critical reader(s) and commentator(s)" of their work.

The students alluded that they face challenges as they get supervised for example, the supervisor does not give feedback to students on time, the students do not have a smooth communication pattern with their supervisor and they do not do drafts but they are asked to produce final products only. The supervisor does not have time to answer questions which their tutees might have. As a result, the students are left with no option but to come up with what they think is right and submit. 


\section{Conclusions and Recommendations}

The objectives of the study were to establish the perceptions of Bachelor degree Honours lecturers regarding research project supervision; capture challenging areas in research project supervision with a view of improving research project supervision and to expand a repertoire of actions and responses. The findings of the study reveals that the key challenges of research supervision for the supervisors lies between the administration part of the research and the expertise. The findings reveal that some supervisors do not have the expertise to supervise research projects and some are of the opinion that the students assigned to them are not form part of their research interests which is always difficult for them to offer the best quality service to their tutees. What we can take from this challenges is that there is a need for a thorough training of research supervisors in their aspects of research supervision and what is expected of them when they supervise students. Moreover, the students need to be taught using a practical approach in year three where they do a module in Educational Research and come up with research proposals in the third year and work towards the research project in year four. The research proposals should form as prerequisites which they have to do in their third year before they progress to the fourth year. The lecturer of Educational Research in year three should ensure that the students have final research proposals which were approved by him /her and present the results to the research coordinator of the university as well as well as to the university's management board for filing. In addition, students need to be scaffolded into becoming independent researchers by ensuring that they know how to write academic research proposals and projects as these skills will be needed in the future when they will have to do their masters and doctorate degrees. Another recommendation from this study will be that the University should start with research modules form year one to year four, this is because one year of doing research is not enough as students learn differently. Let the students do research as they enter the university until they exit. By so doing research will form part and parcel of them. They always say, practice makes perfect. Again, the university of Namibia should develop a strategic plan for enhancing the supervision process at UNAM campuses and the researchers recommend that the university should impose the psysupervision approach where by psy-supervisors serve as resources, not oracles who guide students through their research process and psy-students as novice researchers with the ability to evolve into independent researchers over time. This type of engagement aids in the development of rapport and trust. As a result, both parties can talk about their aspirations and challenges, which might range from academic to socio-emotional issues. 


\section{Acknowledgements}

We would like to thank our almighty God for being the driver as we wrote this paper and for keeping us in good health. Moreover, we extend our major appreciation to the International Journal for Research Publications for accepting our manuscript for publication. This is a milestone and we are grateful.

\section{References}

Agricola, B. T., Prins, F. J., van der Schaaf, M. F., \& van Tartwijk, J. (2021). Supervisor and student perspectives on undergraduate thesis supervision in higher education. Scandinavian Journal of Educational Research, 65(5), 877-897.

Bak, N. (2011). Professionalising the supervision relationship: A reply to Waghid, Fataar and Hugo. South African Journal of Higher Education, 25(6), 1047-1061.

Bartlett, A., \& Mercer, G. (2001). Postgraduate Research Supervision: Transforming (R) Elations. Eruptions: New Feminism across the Disciplines, Volume 11. Peter Lang Publishing, Inc., 275 Seventh Avenue, 28th Floor, New York, NY 10001-6708.

Bastalich, W. (2017). Content and context in knowledge production: a critical review of doctoral supervision literature. Studies in Higher Education, 42(7), 1145-1157.

Bazrafkan, L., Yousefy, A., Amini, M., \& Yamani, N. (2019). The journey of thesis supervisors from novice to expert: a grounded theory study. BMC medical education, 19(1), 1-12.

Brewer, G., Dewhurst, A. M., \& Doran, D. (2012). Undergraduate research projects: Practice and perceptions. Psychology Learning \& Teaching, 11(2), 208-217.

Elmabruk, R., \& Bishti, R. (2020). Returning to Graduation Project: Attitudes and Perceived Challenges of Students and Staff at a Libyan EFL Department. Arab World English Journal, 11 (2) 127-148. DOI: https://dx.doi.org/10.24093/awej/vol11no3.8

Grover, S. F. (2006). Undergraduate research: Getting involved and getting into graduate school (a student's perspective). Eye on Psi Chi, 11(1), 18-20.

Lauridsen, K. M., \& Lauridsen, O. (2018). Teacher capabilities in a multicultural educational environment: an analysis of the impact of a professional development project. International Journal for Academic Development, 23(2), 98-109. 
Lee, A. M. (2007). Developing effective supervisors: Concepts of research supervision. South African Journal of Higher Education, 21(4), 680-693.

Lopatto, D. (2003). The essential features of undergraduate research. Council on Undergraduate Research Quarterly, 23(3), 139-142. https://pdfs.semanticscholar.org/8b47/f05fecb485b85b17d9c371607a3422a822de.pdf

Makoni, P. L. (2021). Novice doctoral supervision in South Africa: an autoethnographic approach. Makoni, PL (2022). Novice doctoral supervision in South Africa: an autoethnographic approach. International Journal of Higher Education, 11(2), 135-142.

Mouton, J. (2001). Research design map. How to succeed in your master's and doctoral studies. Pretoria: Van Schaik, 143-180.

Mushoriwa, T. D., \& Nyakutse, G. (2014). M. Ed graduates' perceptions of thesis supervision, writing and defence. Mediterranean Journal of Social Sciences, 5(8), 319-319.

Muthanna, A., \& Alduais, A. (2021). A Thematic Review on Research Integrity and Research Supervision: Relationships, Crises and Critical Messages. Journal of Academic Ethics, 19(1), 95-113.

Ndlangamandla, S. C. (2017). 'I was not to forget that my reader comes from another world': An Academic Literacies Perspective on Shuttling Between the Workplace and the Academy. Critical Studies in Teaching and Learning, 5(2), 51-68.

Olsson, U., \& Hallberg, D. (2018). Gaps and Overlaps in Supervisory Responsibilities: A Case Study of Bachelor's and Master's Students' Thesis Writing in Two Departments. Journal of Academic Writing, 8(1), 54-71.

Razali, R., Hawe, E., \& Dixon, H. (2020). How are undergraduate students supervised?: Perceptions of students and supervisors in a Malaysian university. Issues in Educational Research, 30(4), 14841501.

Reguant, M., Martínez-Olmo, F., \& Contreras-Higuera, W. (2018). Supervisors' perceptions of research competencies in the final-year project. Educational Research, 60(1), 113-129.

Richardson, J. T., Eysenck, M. W., \& Warren Piper, D. (1987). Student learning: Research in education and cognitive psychology. 
Roberts, L. D., \& Seaman, K. (2018, December). Students' experiences of undergraduate dissertation supervision. In Frontiers in Education (Vol. 3, p. 109). Frontiers.

Sharlanova, V. (2004). Experiential learning. Trakia Journal of Sciences, 2(4), 36-39.

Tello, D. A. C. (2012). The role of zone of proximal development in the students' learning of english adverbs. Journal of Language Teaching and Research, 3(1), 51-57.

Todd, M. J., Bannister, P. \& Clegg, S. (2004). Independent inquiry and the undergraduate dissertation: Perceptions and experiences of final-year social science students. Assessment \& Evaluation in Higher Education, 29(3), 335-355. https://doi.org/10.1080/0260293042000188285

Vereijken, M. W., van der Rijst, R. M., van Driel, J. H., \& Dekker, F. W. (2018). Novice supervisors' practices and dilemmatic space in supervision of student research projects. Teaching in Higher Education, 23(4), 522-542.

Winchester-Seeto, T., Rowe, A., \& Mackaway, J. (2016). Sharing the load: Understanding the roles of academics and host supervisors in work-integrated learning. Asia-Pacific Journal of Cooperative Education, 17(2), 101-118. 